\title{
Habilidades de Estudos Sociais para a professora primária: circulação e apropriação de representações em um projeto de aperfeiçoamento de professores
}

Social Studies Abilities for primary school teachers: circulation and appropriation of representations on a project for the improvement of teachers

Aldaíres Souto França* Juçara Luzia Leite**

\section{RESUMo}

No contexto da implementação do Programa de Assistência Brasileiro-Americana ao Ensino Elementar (PABAEE), foi publicada em 1964 a coleção Biblioteca de Orientação à Professora Primária, composta por diferentes volumes, entre os quais Habilidades de Estudos Sociais, visando ao aperfeiçoamento de professores primários. O presente artigo discute esse livro considerando a noção de habilidades no contexto de formação de professores como parte de um processo de circulação e apropriações de representações de Estudos Sociais como conteúdos e como disciplina escolar. Palavras-chave: história do ensino de História; formação de professores; Estudos Sociais.

\section{Abstract}

In the context of the implementation of Programa de Assistência BrasileiroAmericana ao Ensino Elementar (PABAEE), the collection Biblioteca de Orientação à Professora Primária (Guidelines for Primary School Teachers) was published in 1964, composed by different volumes, among them Habilidades de Estudos Sociais (Social Studies Abilities), aiming at the improvement of primary teachers. This article discusses this book considering the notion of skills in the context of teacher's training as part of a movement of representations and appropriations of Social Studies as content and as a school subject.

Keywords: History of teaching history; teacher training; Social Studies.

\footnotetext{
* Doutoranda em Educação. Universidade Federal do Espírito Santo SEDU/PPGE. Av. Fernando Ferrari, 514. 29075-910 Vitória - ES - Brasil. aldairesouto@yahoo.com.br

** Universidade Federal do Espírito Santo, Departamentos de História e Pedagogia e Programas de Pós-Graduação em História (PPGHis-UFES) e em Educação (PPGE-UFES). Av. Fernando Ferrari, 514. 29075-910 Vitória - ES - Brasil. juju@npd.ufes.br
} 
Em 22 de junho de 1956, sob a articulação de Clóvis Salgado (ministro da Educação), José Francisco Bias Fortes (governador de Minas Gerais) e William Warne (diretor da Operação dos Estados Unidos no Brasil) foi assinado o Programa de Assistência Brasileiro-Americana ao Ensino Elementar (PABAEE). Implementado no Instituto de Educação de Belo Horizonte (Minas Gerais) no período de 1956 a 1964, foi normatizado pela Portaria do MEC no 7 de 1957 e pelo Decreto Legislativo no 16 de 1959.

O envolvimento específico do governo de Minas Gerais, de acordo com Paiva e Paixão, ${ }^{1}$ justificava-se pelo objetivo de reviver a Escola de Aperfeiçoamento que funcionou em Belo Horizonte na década de 1920 e que levou a cidade ao título de Capital Pedagógica do Brasil na época das reformas de Francisco Campos.

Oficialmente, o PABAEE visava à melhoria do ensino fundamental brasileiro por meio da superação dos principais problemas enfrentados, então, pela Educação no Brasil: altos índices de evasão e repetência, elevado número de professores leigos e utilização de material didático que não contribuía para a escolarização. Por professores leigos compreendia-se aqueles que não possuíam formação regular e, de acordo com o Plano Trienal de Educação, "na sua maioria provindos da escola primária”. ${ }^{2}$ O PABAEE considerava, também, atingir as normalistas e os regentes de ensino.

Não obstante a centralidade no ensino fundamental, o PABAEE se preocupou com o ensino secundário. Como resultado disso, em junho de 1957 estabeleceu-se o primeiro convênio com os americanos, com o término previsto para junho de 1964, visando, junto à Diretoria do Ensino Secundário do MEC, o desenvolvimento de centro piloto no Rio de Janeiro com os objetivos de: aperfeiçoar professores secundários; elaborar um programa curricular para o ensino secundário brasileiro; melhorar o material didático utilizado na rede de ensino secundário; pesquisar a possibilidade de criação de mais dois centros de treinamento de professores. ${ }^{3}$

De acordo com Abreu e Eiterer, ${ }^{4}$ mesmo na ausência de estudos mais aprofundados analisando as concepções político-pedagógicas do PABAEE e suas contribuições didáticas, é preciso destacar o material produzido pela equipe do Programa. Esse material era composto, sobretudo, por livros, mas também por artigos em periódicos (criados ou não pelo PABAEE) e até mesmo 
por material audiovisual. Os livros publicados dedicavam-se, em sua maioria, à exposição de conteúdos teórico-metodológicos.

O principal eixo do PABAEE era, assim, a elaboração de materiais e métodos para o ensino-aprendizagem e o aperfeiçoamento de professores para seu uso. Por meio dessas ações, pretendia-se alcançar também soluções para os demais aspectos considerados problemáticos. Nesse contexto, foi publicada a coleção Biblioteca de Orientação à Professora Primária (1964), cuja primeira edição foi realizada pela Editora Nacional de Direito. Os sete volumes da coleção foram escritos por especialistas formados no Curso de Educação Elementar oferecido na Universidade de Indiana (Estados Unidos) visando ao aperfeiçoamento de professores, administradores e supervisores escolares do ensino primário, conforme informação fornecida na contracapa dos livros.

Essa coleção foi produzida para ser usada por educadores, principalmente professores de Metodologia e Prática de Ensino no planejamento de suas aulas, ou seja, no processo formativo de professores. Era constituída por volumes de capa dura, todos com ilustrações referentes aos temas abordados: Ver, sentir, descobrir a Aritmética, de Rizza Araújo Porto (com 166 páginas); Experiências de Linguagem Oral, de Maria Yvonne Atalécio de Araújo (com 274 páginas); Habilidades de Estudos Sociais, de Maria Onolita Peixoto (com 186 páginas); Formação e desenvolvimento de conceitos, de Maria Luiza de Almeida Couto Ferreira (com 192 páginas); Testes, medidas e avaliação, de Oyara Petersen Esteves (com 206 páginas); O que é Jardim de Infância, de Nazira Feres AbiSáber (com 186 páginas); e Ciências na Escola Moderna, de Maria José Berutti e Terezinha Nardell (com 279 páginas).

Neste artigo analisaremos o volume Habilidades de Estudos Sociais considerando o contexto de sua produção e a circulação e apropriação de representações de Estudos Sociais, presentes na constituição de uma cultura escolar. $^{5}$

\section{UMA PROFESSORA-AUTORA}

Ampliando o raciocínio de Boto ${ }^{6}$ sobre o professor primário português no século XIX, pensamos os professores autores de livros didáticos e manuais de ensino como um grupo específico integrante da própria constituição da 
cultura escolar. Dessa forma nos questionamos: quem era a professora Maria Onolita Peixoto? ${ }^{7}$ De que lugar produzia sua escrita?

Ao considerarmos a autora e sua produção relacionalmente, apresentamos aqui um exercício de situá-las no contexto das representações, apropriações e práticas de escrita didática de professoras da década de 1960. Nesse sentido, compreendemos o livro Habilidades de Estudos Sociais como objeto cultural que dá a ler uma dada representação de Estudos Sociais para a normatização da disciplina e para o aperfeiçoamento de professores primários.

Maria Onolita Peixoto atuava como orientadora educacional e era formada no Curso de Orientadora Técnica e Administração Escolar do Instituto Educacional de Minas Gerais. Também era Técnica de Didática de Estudos Sociais do PABAEE e, para obter essa especialidade, participou do Curso de Educação Elementar na Universidade de Indiana (Estados Unidos). Em decorrência dessa formação, atuava no Departamento de Estudos Sociais do PABAEE ministrando cursos de aperfeiçoamento de professores.

Como parte das ações oriundas de seu curso em Indiana, verificamos que participou de uma comissão interdepartamental cujo objetivo era, em caráter experimental, o planejamento curricular de uma classe de $5^{\circ}$ ano do Grupo Escolar do Instituto de Educação de Belo Horizonte em 1956. Além disso, compôs a equipe de representantes do PABAEE, realizando viagens ao Nordeste do Brasil, especificamente ao Ceará e Rio Grande do Norte, entre 30 de novembro e 6 de dezembro de 1958, objetivando a divulgação dos trabalhos desenvolvidos pelo PABAEE. Em Natal, participou da elaboração do Relatório de Visita enviado à Secretaria de Educação, além de diversas atividades técnicas junto a essa Secretaria.

Em 1967, Maria Onolita Peixoto esteve entre os 17 nomes credenciados que participaram da Comissão de Especialistas responsáveis pela seleção de livros para compor as "Bibliotecas-amostra", implantadas pela Comissão de Livros Técnicos e Didáticos (Colted). Os demais participantes foram: Cândida Luiza Cerne de Carvalho (professora de História e Filosofia da Educação da Escola Normal Carmela Dutra); Eunice da Conceição Macedo Rosa (professora de Português e integrante da equipe de assistência ao Ensino Primário MECUsaid); Heloisa Feital dos Reis (professora de Educação Física e Recreação no Curso Normal do Instituto de Educação da Guanabara); Leny Werneck Dornelles (professora de Teoria e Prática da Escola Primária na Cadeira de 
Prática de Ensino do Curso de Formação de Professores para o Ensino Normal do Instituto de Educação da Guanabara); Maria Augusta Joppert (professora de Educação Musical da Secretaria de Educação e Cultura da Guanabara); Maria Helena Novais (psicóloga do ISOP da Fundação Getulio Vargas); Maria José Berutti (professora de Didática de Ciências Naturais do Centro Regional de Pesquisas Educacionais João Pinheiro, de Belo Horizonte); Maria José Penna Firme (professora de Psicologia do Colégio Estadual Camilo Castelo Branco); Maria Luiza de Almeida Cunha Ferre (professora contratada do Instituto Central de Ciências Humanas da UFMG); Maria Vicentina de Campos Carvalho (professora da cadeira "Educação Alimentar" do Curso para Supervisores do Programa de Educação e Assistência Alimentar em Belo Horizonte); Nair Ferreira Tulha (professora de Matemática do Instituto de Educação da Guanabara); Newton Dias dos Santos (professor catedrático de Metodologia da História Natural e Ciências da Universidade Gama Filho); Norma Cunha Osório (professora da Secretaria de Educação e Cultura do Estado da Guanabara); Maria Yvonne Atalécio de Araújo (professora de Didática da Linguagem); Lydinéa Gasman (professora do Colégio Pedro II e professora de Didática de História da Faculdade Nacional de Filosofia), e Terezinha de Jesus Casasanta (professora de Didática do Curso Colegial Normal do Instituto de Educação de Belo Horizonte). ${ }^{8}$

Assim como essa Comissão de Especialistas, pensamos os autores da coleção Biblioteca de Orientação à Professora Primária como uma comunidade de interpretação, professores-autores que compartilham experiências e relações sociais específicas em determinado contexto histórico e cultura escolar. Assim, formaram um grupo que a despeito das trajetórias de vida pessoais encontrou-se em um objetivo comum: o aperfeiçoamento de professores previsto no PABAEE.

No quinquênio de 1956 a 1960, administradores de sistemas escolares; especialistas em educação primária; supervisores, diretores e professores de escolas normais; diretores e professores de escolas de demonstração e experimentais; supervisores, diretores de oficinas e professores de artes industriais; professores especializados; e professores primários de classe em geral participaram dos cursos oferecidos pelo PABAEE, todos divulgados na imprensa oficial. Os cursos eram realizados em diferentes Centros Regionais, mas a sede do PABAEE no Brasil permaneceu no Instituto de Educação de Belo Horizonte. 
As despesas (custo com pessoal, material de ensino, auxílio aos bolsistas dos vários estados brasileiros) eram subsidiadas pelo Instituto Nacional de Estudos e Pedagógicos (Inep), que também financiou, anualmente, a viagem dos professores que foram se aperfeiçoar nos Estados Unidos.

Os cursos oferecidos prioritariamente pelo Inep foram:

- Especialistas em educação para a América Latina. Realizado anualmente, a partir de 1958, no Centro Regional de São Paulo, em colaboração com a Unesco, com a participação de 86 bolsistas (45 brasileiros e 41 latino-americanos);

- Aperfeiçoamento de Supervisores de Educação Rural e Orientadores-Adjunto. No Centro Regional de Minas Gerais, vagas oferecidas a 38 bolsistas;

- Supervisores do ensino primário, que ocorreu na Paraíba e no Rio Grande do Sul e teve 37 participantes;

- Diretores de escolas de demonstração, que aconteceu na Bahia e teve quatro participantes;

- Inspetores do ensino primário, cursos que ocorreram no Espírito Santo e em São Paulo, com a participação de 115 inspetores;

- Administradores escolares e Orientadores de ensino, oferecidos no Rio Grande do Norte e em São Paulo, com 185 participantes;

- Diretores de escolas primárias, na Paraíba e no Piauí, com 62 participantes;

- Aperfeiçoamento de professores primários, em Alagoas, na Bahia, Ceará, Espírito Santo, Maranhão, Pernambuco, Piauí, Rio Grande do Norte, Sergipe e Território de Rondônia, com 3.509 participantes;

- Aperfeiçoamento em cadeiras do currículo primário (Linguagem, Matemática, Ciências Naturais e Estudos Sociais), oferecido na Guanabara e no Rio Grande do Sul, com 79 participantes;

- Curso para professores de escolas normais e orientadores de ensino, que aconteceu em Minas Gerais e no Paraná, com 250 participantes.

Os cursos de aperfeiçoamento (nos Estados Unidos e no Brasil) eram espaços de circulação de representações e ideias norte-americanas sobre uma educação a ser efetivada no país. As alternativas propostas, entretanto, não 
consideraram a história e a cultura escolar brasileira, gerando, segundo Paiva e Paixão (2002), insatisfação entre os profissionais dos Institutos de Educação. Não obstante serem registradas situações de resistência, nosso objetivo, aqui, é compreender o Habilidades de Estudos Sociais como parte das estratégias formativas de professores primários no contexto do PABAEE.

\section{Circulação e apropriação de determinados 'Estudos Sociais'}

O livro Habilidades de Estudos Sociais, como os demais da coleção Biblioteca de Orientação à Professora Primária, era representado por um símbolo, nesse caso o globo terrestre. Partimos do pressuposto de que essa escolha já anunciava a apropriação das ideias de John Michaelis ${ }^{9}$ para o ensino de Estudos Sociais no ensino primário, especialmente o livro Estudos Sociais para crianças numa democracia. Compreendemos que o processo de apropriação não pode ser visto como mera transposição de ideias e representações, mas encerra um processo de ressignificação. Dessa forma, de acordo com a professora-autora:

Hoje, Estudos Sociais podem ser definidos como sendo o estudo do homem e de todos os seus problemas nas suas relações com outros homens e com o seu ambiente. Segundo John Michaelis, os Estudos Sociais "são estudos concernentes às pessoas e sua inteiração [sic] com meio físico e social; são estudos que tratam das relações humanas". Como apresentar um assunto tão complexo à capacidade infantil? De que forma seriam vistos os variados problemas envolventes do homem num programa da Escola Primária? Estas e outras seriam perguntas a pedir solução. Dentre alguns educadores e sistematizadores dos últimos anos, salienta-se John Michaelis, que fundamenta um programa de Estudos Sociais mostrando implicações históricas, sociológicas, antropológicas, geográficas, econômicas, cívicas e políticas no estudo de um caso, ou seja, de uma área de estudo. Mostra-as sob a forma de funções sociais ou atividades do homem. Classificou em 10 as principais funções sociais do homem: Produção, Distribuição, Transporte, Comunicação, Governo, Educação, Conservação, Expressão Estética, Religião, Recreação. (Peixoto, 1964, p.17)

O estudo da interação do homem com seu meio físico e social vai ser desta forma dimensionado no trabalho da professora Maria Onolita 
Peixoto: produção, distribuição, transporte, comunicação, governo, educação, conservação, expressão estética, religião e recreação. Peixoto ainda esclarece, no que se refere à sua compreensão de aprendizagem: "Todas as habilidades aqui destacadas [na obra] foram treinadas pelas crianças e professoras da Escola de Demonstração do Instituto de Educação e nos permitiram ver o quanto e o como podem nossas crianças se adestrar para o bem aprender" (Peixoto, 1964, p.11).

Observamos, assim, que a apropriação das ideias de John Michaelis sofre uma adaptação no trabalho de Maria Onolita Peixoto, uma vez que o pensamento do americano fundamentava-se na Psicologia de Desenvolvimento da Criança com base na discussão sobre aprendizagem como um processo em que a criança modifica o seu comportamento à medida que realiza propósitos importantes e significativos. Maria Onolita Peixoto, diferentemente, evidencia a apropriação da Psicologia Behaviorista com ênfase no adestramento social da criança.

A professora-autora apresenta também os objetivos da metodologia dos Estudos Sociais na Escola Primária, isto é: a aprendizagem das habilidades próprias da área, bem como a visão geral das 'habilidades sociais' e das 'habilidades específicas de conteúdo' ou 'habilidades de estudo' a serem desenvolvidas. Pensamos que sua finalidade é chamar a atenção para a dimensão prioritária das 'habilidades', conforme o título do livro, e orientar a 'professora primária a ampliá-las, na medida do possível'. As expressões de que 'as habilidades foram treinadas pelas crianças' demonstra uma centralidade no experimento como forma de desenvolver o conhecimento. Nessa concepção, Peixoto se aproxima mais uma vez das ideias de Michaelis.

Ainda no exercício de manifestação da sua singularidade na apropriação da obra de John Michaelis, Maria Onolita Peixoto explica que a Geografia e a História não são as únicas fontes de explicações das relações humanas. Para tanto, salienta que os programas de Estudos Sociais mostram implicações históricas, sociológicas, antropológicas, geográficas, econômicas, cívicas e políticas no estudo das relações humanas. Nessa perspectiva, os Estudos Sociais na Escola Primária deveriam:

levar a criança à compreensão dos fatos e situações de vida, ajustando-se a seu meio, inteirando-se nos grupos a que vem pertencer, convivendo com os outros, 
resolvendo e vencendo os seus próprios problemas ... Cumpre formar e desenvolver uma mentalidade sadia em torno de tão poderosos instrumentos de progresso [Ciência e Tecnologia]; que eles não sejam destruidores da Humanidade, mas exijam e obtenham dela alto senso de dever público, conhecimento esclarecido para as forças e aplicação do bem ... Educar para uma Democracia - educar para viver democraticamente, isto é, em bases de cooperação e ajuda mútua, de respeito à integridade individual e responsabilidade social, constituem, pois tarefa de relevo na época atual. (Peixoto, 1964, p.18-19)

A professora-autora remete-se à procedência norte-americana de sua concepção dos Estudos Sociais explicitando a necessidade de adequar o currículo dessa disciplina às exigências da época. Dessa forma, quanto ao conteúdo, às técnicas e ao modo de 'preparar e habilitar o educando' de forma satisfatória, acrescenta: "a tendência de seu currículo na Escola Moderna é seguir objetivos de modo que se trace um programa, cujas bases de estruturação e metodologia sejam condizentes com as necessidades atuais" (Peixoto, 1964, p.20).

Além da influência explícita de John U. Michaelis, percebe-se que, em Habilidades de Estudos Sociais, Maria Onolita Peixoto dialoga com outros sete autores norte-americanos cujas obras constam da bibliografia relacionada ao final de seu livro em sessão denominada "Livros consultados". Como esses títulos são listados em versão original, acreditamos que isso aponte para uma leitura efetivada na ocasião da realização dos cursos de especialização do PABAEE nos Estados Unidos. Dentre esses, destaca-se o Ensinando estudos sociais na escola primária, de Ralph C. Preston. ${ }^{10}$

Consta também da relação de livros consultados pela professora-autora o livro Human development and education, de Robert James Havighurst. ${ }^{11}$ Esse destaque é importante uma vez que foi Havighurst um conceituado cientista do comportamento, tendo identificado tarefas de desenvolvimento que as pessoas desempenham à medida que crescem e amadurecem. Segundo esse autor, mesmo que as pessoas não tenham conhecimento de que realizam tais tarefas de desenvolvimento, a maneira pela qual executam essas tarefas ajuda a determinar suas personalidades em geral. Dessa forma, o sucesso nessas tarefas levaria à felicidade e ao sucesso em outras tarefas de desenvolvimento que irão executar mais tarde na vida.

Havighurst também identificou seis grandes etapas da vida humana desde o nascimento até a velhice, destacando-se aquelas implicadas naquilo que se 
compreendia ser, então, a vida escolar: infância e primeira infância (nascimento até os 6 anos de idade), meia infância (6-13 anos) e adolescência (13-18 anos). Delineou tarefas de desenvolvimento para cada estágio de uma pessoa, compreendendo que a criança deveria aprender a se tornar um adulto digno e produtivo mediante restrições colocadas sobre ela pela sociedade. No Brasil, Havighurst atuou em pesquisas organizadas pelo Inep, tendo publicado obras em parceria com educadores brasileiros, inclusive sobre ensino secundário. Os seus estudos sobre a educação influenciaram a natureza da escolarização nos Estados Unidos e outros autores norte-americanos de sua geração.

Compreendemos que as apropriações das ideias de John Michaelis para o ensino de Estudos Sociais no ensino primário realizadas por Maria Onolita Peixoto e expressas em seu livro Habilidades de Estudos Sociais apresentam influências de Preston e Havighurst. Por isso pode-se perceber as distinções entre o pensamento dos americanos e da brasileira e a interseção da Psicologia do Desenvolvimento com a ênfase no 'adestramento' das crianças.

Dessa forma, Peixoto construiu uma argumentação sobre o desenvolvimento da aprendizagem da criança que parece dialogar com o referencial de Havighurst. Tais argumentos desdobram-se em sua análise sobre a noção de 'habilidades', bem como no relacionamento com os aspectos da aprendizagem e no processo de mudança no comportamento do indivíduo, provocando outra compreensão do arranjo teórico constituído na obra de Michaelis.

Em decorrência dessas apropriações, a professora-autora desloca o foco de sua abordagem do currículo do conteúdo para a aprendizagem da criança, destacando o desenvolvimento das potencialidades infantis com base na experiência e em experimentos. Assim, mesmo argumentando que a aprendizagem difere de uma criança para outra, procura traçar padrões que podem variar segundo as diferenças de "prontidão, potencial e experiência" (Peixoto, 1964, p.20). Argumenta, ainda, sobre a importância de o professor conhecer a criança, suas necessidades e as possibilidades de que dispõe para que seja possível a orientação no processo de aprendizagem por meio do desenvolvimento de habilidades.

De acordo com Maria Onolita Peixoto:

Dizem os dicionários que "Habilidade" é a qualidade de quem é hábil, é a "capacidade que alguém tem de fazer alguma coisa", "é destreza”, etc. Os educadores 
modernos, no entanto, reconhecendo a tese da aprendizagem, veem na "Habilidade" a facilidade de fazer alguma coisa. Toda criança pode ter, aprender e desenvolver habilidades. E mais: as crianças possuem habilidade criadora em vários estágios de desenvolvimento. Hoje a criatividade é considerada mais uma coisa de grau antes que de espécie ... o ato criador é primariamente alguma expressão que é nova para o indivíduo ou um melhoramento sobre sua expressão passada ... É sobre este prisma, isto é, como o da facilidade para fazer alguma coisa, ou da capacidade de realizar uma ideia, ou praticar uma ação, que iremos tratar do assunto de "Habilidades" em Estudos Sociais. (Peixoto, 1964, p.22)

Percebe-se, assim, a vinculação de uma dada representação dos Estudos Sociais como disciplina escolar a um conteúdo pluridisciplinar, cívico e axiológico, e à representação de uma educação moderna que deveria formar professores modernos mediante o desenvolvimento de habilidades. Para a professora-autora, os critérios para a seleção das habilidades para Estudos Sociais modernos deveria considerar o fato de serem possíveis de se desenvolver (Peixoto, 1964, p.22-23):

- através de situações nas quais os alunos vejam uma real necessidade para elas;

- considerando a prontidão do educando;

- através de situações em que os alunos possam usá-las funcionalmente;

- através de situações que permitam à criança crescer na compreensão dos princípios que regem o uso de tal habilidade;

- dentro de uma sequência lógica de dificuldades, quando se trata de habilidades específicas da matéria;

- continuamente;

- através de toda experiência possível de aprendizagem, para proporcionar melhor assimilação.

Pensamos que o pressuposto de Maria Onolita Peixoto era que o programa de Estudos Sociais deveria se preocupar com: quais habilidades (de que tipo) deveriam ser formadas e desenvolvidas em Estudos Sociais; quando desenvolver tais habilidades; através de quais experiências seriam elas desenvolvidas; e quais materiais seriam necessários para desenvolver habilidades em 
Estudos Sociais. Mais uma vez se distingue de Michaelis, o qual propunha um programa de Estudos Sociais que promovesse o desenvolvimento das crianças e dos jovens considerando o desenvolvimento de atitudes (bem como de compreensões, aptidões, conceitos, apreciações e conhecimentos construtivos essenciais à vida democrática): Peixoto enfatiza a socialização da criança com a finalidade de atender a expectativas sociais de uma sociedade comprometida com um desenvolvimento econômico em expansão. Em suas palavras:

A socialização tem também aspectos ativos e construtivos: anima, interessa, motiva, leva o indivíduo a desejar a disputar, a desenvolver e realizar. Em termos gerais, a socialização é, pois, ao mesmo tempo, processo modelador e criador que promove mudanças de comportamentos individuais, de acordo com os valores ditados pela sociedade. (Peixoto, 1964, p.29)

Quanto às chamadas habilidades específicas de conteúdo, é possível observar, principalmente, sua relação com os conhecimentos relacionados à Geografia: leituras de mapas, do globo, de escala, a explicação sobre o movimento da terra em redor do sol, a observação da direção do sol e a interpretação de gráficos, por exemplo.

Na singularidade da escrita de Maria Onolita Peixoto, observamos que as habilidades específicas relacionadas aos conhecimentos da História limitaram-se à noção de tempo, de geração e organização dos períodos e fatos da História do Brasil em uma linha do tempo. Assim, de acordo com o livro Habilidades de Estudos Sociais, a linha do tempo seria um recurso didático que auxiliaria a criança a compreender fatos conceituais de tempo e cronologia em uma dada situação. A cronologia, no entendimento da professora-autora, podia se reduzir a um arranjo de acontecimentos numa sequência de tempo, envolvendo uma compreensão das diferenças entre as datas. Esse estudo deveria ser iniciado no jardim de infância e seguir gradativamente no decorrer da escola primária, considerando as diferentes etapas do desenvolvimento das habilidades na infância.

Considerando esse desenvolvimento, orientava-se que no $2^{\circ}$ ano a criança estudasse a história da sua cidade, e, no $3^{\circ}$ ano, a história do seu estado. Peixoto considerava que essa sequência seria como uma volta ao passado, depois que a criança pudesse compreender as relações estabelecidas com a vida presente, e de acordo com uma concepção linear dos acontecimentos históricos. Para 
evitar a simples memorização de datas e nomes, Peixoto afirmava que a criança deveria guardar as datas de sua História, da Pátria, da cidade e de seu estado, por meio de processos associativos com outros acontecimentos.

No $4^{\circ}$ ano, por sua vez, a criança aprenderia outros conceitos e noções relacionados à compreensão da cronologia, como, por exemplo, a noção de século. Dessa forma, exercitaria a habilidade de comparar e diferenciar épocas, utilizando-se do conceito de geração e realizando atividades práticas com base na data de nascimento de familiares. Além disso, Maria Onolita Peixoto estabeleceu princípios básicos para nortearem a construção de uma linha do tempo, considerando que "há necessidade de levar a criança a 'realizar bem' a sua tarefa, com técnica, com exatidão, com ordem e com capricho" (Peixoto, 1964, p.109). Tais princípios se faziam acompanhar de indicações precisas sobre, por exemplo, a necessidade de se obedecer a uma escala $(1 \mathrm{~cm}$ representando 1 hora, ou 1 ano ou 1 século), para que a linha do tempo seja apropriada ao objetivo do assunto abordado, além de ser "simples, atraente e original" (Peixoto, 1964, p.109).

O sucesso no ensino e na aprendizagem seriam garantidos pelo fato de seguirem essas orientações fundamentadas em dada representação de Estudos Sociais e apropriadas com base em um referencial composto por diferentes pensadores norte-americanos cujos trabalhos circularam entre os professores aperfeiçoados pelo PABAEE.

\section{Algumas CONSIDERAÇÕES}

Compreendemos que a coleção Biblioteca de Orientação da Professora Primária evidencia uma proposta técnica visando ao 'aperfeiçoamento' da professora primária concebida como a preparadora do futuro desenvolvimentista do país por meio da formação do cidadão 'útil'.

Conforme já mencionado, para Maria Onolita Peixoto o ensino de Estudos Sociais seria responsável por socializar a criança e transformá-la em um adulto útil e produtivo, por meio do trabalho, da solidariedade social e da cooperação, ou seja, por meio do 'treinamento social' ou 'ajustamento do comportamento’ da criança às expectativas sociais. Essa concepção estava de acordo com sua visão sobre a Escola Primária cuja tarefa principal seria o desenvolvimento eficiente de 'habilidades básicas sociais'. Para alcançá-las, a autora argumentava que a melhor maneira possível seria a promoção de experiências 
em situações sociais, ou seja, por meio do trabalho em conjunto, cooperativamente, dividindo responsabilidades e partilhando ideias. Essas experiências, isto é, "o valor da cooperação e da responsabilidade, a necessidade de tolerância e respeito pelas opiniões e ideias dos outros, a compreensão de aceitação de críticas, o uso do pensamento crítico, etc." (Peixoto, 1964, p.28), ainda de acordo com a professora-autora, deveriam ser aprendidas na escola.

Esse conjunto de ideias ganha sentido mais amplo se inserido na concepção que Peixoto apresenta para uma escola primária que teria a função de desenvolver a criança em dois aspectos prioritários:

primeiro, o de aprendizagem social ou socialização, pelo qual a criança aprende todas as coisas que deve ou não fazer para se tornar um membro útil da sociedade ... e responde pelos seus deveres. O segundo aspecto do desenvolvimento social é a formação de vínculos sociais ou a expansão do horizonte social da criança. Ela aprende a incluir maior número de pessoas no grupo a que pertence, ou, em outras palavras, expande o seu horizonte social, compreendendo, à medida que cresce, que é um cidadão da comunidade local do Estado, da Nação e do Mundo. (Peixoto, 1964, p.28)

Diante disso, observamos que a professora-autora lança mão, ao se apropriar de diferentes pensadores norte-americanos, de dispositivos para criar um suposto consenso que residiria na dimensão das habilidades individuais dos alunos. Consequentemente, produz um velamento sobre a concepção de História, ou melhor, descaracteriza os conhecimentos históricos, enfatizando apenas habilidades sociais e comportamentais como, por exemplo: o processo de trabalho em grupo, a troca de ideias ou discussão informal, a construção de materiais e a solução de problemas.

Considerando a sua relação com o PABAEE e com a circulação das publicações norte-americanas, sua obra também está inserida no contexto da implantação dos Estudos Sociais por meio de estratégias utilizadas para legitimar uma educação que atendesse ao ideal liberal de desenvolvimento econômico característico desse contexto histórico. De forma inventiva, tomando por base o proposto por Michaelis, que apresentou uma proposta de ensino de Estudos Sociais sob a expectativa de um projeto de sociedade democrática, ela escreve e publica imersa em sociedade que vivia as tessituras de uma ditadura militar. 


\section{NOTAS}

${ }^{1}$ PAIVA, Edil; PAIXÃO, Léa P. PABAEE (1956-1964): a americanização do ensino elementar no Brasil. Niterói (RJ): Eduff, 2002; este dialoga com o conceito de Chartier (2000, 2009). CHARTIER, Roger. El orden de los libros: lectores, autores, bibliotecas en Europa entre los siglos XIV y XVIII. Trad. Viviana Ackerman. Barcelona: Gedisa, 2000.

CHARTIER, Roger. A história ou a leitura do tempo. Trad. Cristina Antunes. Belo Horizonte: Autêntica, 2009.

2 BRASIL. Plano Trienal de Educação (1963-1965). Brasília, 1963. p.11. Disponível em: www.dominiopublico.gov.br/pesquisa/DetalheObraForm.do?select_action=\&co_ obra=28771; Acesso em: 10 nov. 2012.

${ }^{3}$ TAVARES, José Nilo. Educação e imperialismo no Brasil. Educação e Sociedade, n.7, p.552. São Paulo: Cedes, set. 1980.

${ }^{4}$ ABREU, Claudia Bergerhoff L.; EITERER, Carmem Lucia. A ênfase metodológica na formação de professores do PABAEE. Linhas, Florianópolis: Udesc, v.9, n.1, p.93-108, jan.-jun. 2008. Disponível em: www.periodicos.udesc.br/index.php/linhas/article/viewFile/1367/1173; Acesso em: 10 nov. 2012.

${ }^{5}$ JULIA, Dominique. A cultura escolar como objeto histórico. Revista Brasileira de História da Educação, Campinas (SP), n.1, p.9-45, 2001.

${ }^{6}$ BOTO, Carlota. O professor primário português como intelectual: eu ensino, logo existo. Revista da História das Ideias, Coimbra: Faculdade de Letras, v.24, p.85-134, 2003.

${ }^{7}$ PEIXOTO, Maria Onolita. Habilidades de Estudos Sociais. Rio de Janeiro: Ed. Nacional de Direito, 1964.

${ }^{8}$ KRAFZIK, Maria Luiza de Alcântara. Acordo MEC/Usaid: a Comissão do Livro Técnico e do Livro Didático - Colted (1966/1971). Dissertação (Mestrado em Educação) - Programa de Pós-Graduação em Educação, Universidade do Estado do Rio de Janeiro. Rio de Janeiro, 2006. p.79.

${ }^{9}$ MICHAELIS, John. Estudos sociais para crianças numa democracia. Trad. Leonel Vallandro. Rio de Janeiro: Globo, 1963.

${ }^{10}$ PRESTON, Ralph C. Ensinando estudos sociais na escola primária. Rio de Janeiro: MEC/ Usaid, 1964.

${ }^{11}$ HAVIGHURST, Robert James. Human development and education. New York: Longmans, Green and Co., 1953.

Artigo recebido em 20 de dezembro de 2012. Aprovado em 14 de abril de 2013. 